\title{
Regulatory authorities and orthopaedic clinical trials on expanded mesenchymal stem cells
}

\author{
Enrique Gómez-Barrena • Cristina Avendaño Solá • \\ Carmen Painatescu Bunu
}

Received: 14 March 2014 / Accepted: 16 March 2014 / Published online: 15 April 2014

(C) The Author(s) 2014. This article is published with open access at Springerlink.com

\begin{abstract}
Skeletal injuries requiring bone augmentation techniques are increasing in the context of avoiding or treating difficult cases with bone defects, bone healing problems, and bone regeneration limitations. Musculoskeletal severe trauma, osteoporosis-related fractures, and conditions where bone defect, bone collapse or insufficient bone regeneration occur are prone to disability and serious complications. Bone cell therapy has emerged as a promising technique to augment and promote bone regeneration. Interest in the orthopaedic community is considerable, although many aspects related to the research of this technique in specific indications may be insufficiently recognised by many orthopaedic surgeons. Clinical trials are the ultimate research in real patients that may confirm or refute the value of this new therapy. However, before launching the required trials in bone cell therapy towards bone regeneration, preclinical data is needed with the cell product to be implanted in patients to ensure safety and efficacy. These preclinical studies support the end-points that
\end{abstract}

E. Gómez-Barrena

Department of Orthopaedic Surgery and Traumatology, Hospital La

Paz and Universidad Autónoma de Madrid, Madrid, Spain

C. A. Solá

Department of Clinical Pharmacology, Hospital Puerta de Hierro-Majadahonda and Universidad Autónoma de Madrid, Madrid, Spain

C. P. Bunu

Victor Babes University of Medicine and Pharmacy Timisoara, Timisoara, Romania

E. Gómez-Barrena $(\bowtie)$

Cirugía Ortopédica y Traumatología, Hospital La Paz, Universidad

Autónoma de Madrid, P Castellana 261, 28046 Madrid, Spain

e-mail: egomezbarrena@gmail.com

E. Gómez-Barrena

e-mail: enrique.gomezbarrena@uam.es need to be evaluated in clinical trials. Orthopaedic surgeons are the ultimate players that, through their research, would confirm in clinical trials the benefit of bone cell therapies. To further foster this research, the pathway to eventually obtain authorisation from the National Competent Authorities and Research Ethics Committees under the European regulation is reviewed, and the experience of the REBORNE European project offers information and important clues about the current Voluntary Harmonization Procedure and other opportunities that need to be considered by surgeons and researchers on the topic.

Keywords Bone regeneration - MSC · AMTP - European regulation $\cdot$ Clinical trials $\cdot$ Cell therapy

\section{Introduction}

Bone healing augmentation through bone regeneration seeks to repair or replace damaged bone, with the goal to fully restore structure and function. While cell-based therapies are promising new therapeutic approaches, their clinical application is still under discussion. The burden of skeletal injuries and bone diseases that could benefit from regenerative medicine approaches includes not only bone defects of traumatic origin, but also bone healing delays and nonunions, osteonecrotic damage, or other situations where bone regeneration is required but osteogenic potential is insufficient.

By using mesenchymal stem cells (MSCs), good results have been reported for bone engineering in a number of early clinical studies [1], most of them investigator-initiated trials with limited scope with respect to controls and outcome. With the implementation of a new regulatory framework for advanced therapeutic medicinal products (ATMPs) in Europe, both the characterization of the cells and combination products need to be more clearly defined. Well-designed clinical 
trials (CT) are expected to clarify the safety and efficacy issues with specific cell products in specific indications.

Significant investment has been dedicated to bone regenerative medicine. Although tremendous efforts have been conducted in basic research, leading to the reinforcement of developmental bone cell biology knowledge, very limited if any patient benefit has been clearly obtained up-to-date. The time of opportunities has come for clinical translation of these advancements, and progress towards definite clinical applications might be the most genuine pathway to foster this research in the benefit of our patients. The orthopaedic surgeon requires specific information about the state of the art on clinical applications of this therapy and ongoing research that will soon be ready to incorporate new solutions to the orthopaedic armamentarium. Furthermore, the practising surgeons need also to be aware of the opportunities and barriers to offer their patients the best care based on the best available scientific knowledge, and how to develop the required evidence when insufficient.

Through this review, we will consider the orthopaedic bone injuries that could constitute opportunities for bone regeneration techniques, the studies that are needed to establish a wellsupported bone cell therapy through the definition of safety, feasibility and efficacy end-points, the role of investigatordriven clinical trials (IDCT) in advanced therapy medicinal products for bone, and the current multinational regulatory pathway in Europe, as followed by the REBORNE trials, through a national approach and through the European voluntary harmonization procedure.

\section{Skeletal injuries: opportunities for bone regeneration}

Epidemiological reports such as the Global Burden of Disease [2], the WHO Technical series [3] and derived publications [4] stress the fact that musculoskeletal conditions and bone injuries are significant causes of disability worldwide.

The Bone and Joint Decade [5, 6] has contributed to focus on the most prevalent and complex orthopaedic problems. The conjoined efforts developed by researchers and clinicians, institutions, and countries have increased the awareness and the interest in the present and future solutions to these problems. Particularly, bone repair and healing advancements have been focused through the Bone and Joint Decade on the management of musculoskeletal trauma, the reconstruction of osteoporosis-related fractures, and the high number of surgically-treated spine disorders requiring fusion and refusion.

Musculoskeletal severe trauma requires structural support and bone healing enhancement, particularly in complex cases, to avoid or treat bone healing complications. Especially traumatic bone defects associated with high energy fractures after traffic accidents are a devastating problem all over the world.
Thirteen bone injuries were among the 20 leading non-fatal injuries sustained after road traffic accidents worldwide in 2002 [4], estimating $25 \%$ of total health expenditures in developed nations. Furthermore, a significant change in the rank order of disability-adjusted years (DALYs, measuring loss of health from disability) has been found from 1990 with traffic injuries being the ninth cause and potentially becoming the third cause in 2020. Disability frequently associates bone healing fracture-related problems such as nonunion, at a rough $5 \%-10 \%$ rate. Delayed unions and nonunions after fracture may relate to biomechanical factors that can be solved through modifications of surgical technique, but the bone capability to consolidate through regeneration may be compromised when insufficient osteogenic reaction is observed in the fracture callus, and an atrophic nonunion may develop. In those cases, and provided vascular status and skin coverage are preserved or recovered, biological potential for osteogenesis relying on osteoprogenitor cell lines determines adequate healing. In the United Kingdom, 850,000 new fractures are seen in a year, but the overall regional nonunion incidence rate has been reported in 18.9/100,000 population/year [7].

Osteoporosis-related fractures also require bone defect filling and structural support, and this epidemy in industrialized countries is especially aggressive in Northern Europe, where $46.4 \%$ of females over 65 are predicted to have a fragility fracture (proximal femur, proximal humerus, distal radius, vertebral bodies) [8], but also in Southern Europe [9], where some of these are associated to complications with trabecular compression and derived bone defects, but also related to suboptimum healing potential. Metaphyseal osteoporotic fracture may then result in poor fixation with secondary displacement of internal fixation devices in spite of blocking screws and other developments. In case of diaphyseal osteoporotic fracture, decreased cortical thickness and increased canal diameter also may derive into delayed consolidation or nonunion. In the specific case of periprosthetic fractures, usually metaphyseal and/or diaphyseal, thin sclerotic bone supporting the implant may also find difficulties to complete consolidation. A decreased number of osteoprogenitors are associated with advanced age where osteoporosis peaks, could be the underlying cause and may benefit from future regenerative solutions. All these circumstances are potential applications that may be the case for future trials.

Other conditions where bone collapse occurs, with limited bone regeneration capabilities such as primary or secondary bone osteonecrosis frequently associated with avascular necrosis or corticotherapy, have long been the case of cell therapy approaches. Current solutions and options, in different patient categories and underlying diseases, are also the case for opportunities of basic and clinical research, as the efficacy is highly variable.

Decreased biological capabilities in the injured or diseased bone are the most interesting therapeutic targets for advanced 
bone healing augmentation techniques. However, to progress towards clinical application, in any of the hypotheses, preclinical data and regulatory approvals are needed and will be discussed in the following sections.

\section{Bone cell therapy: what preclinical studies are needed}

Bone cell therapies have been proposed as alternatives to bone grafting, in which mesenchymal cells in the early phases of the osteogenic line are transferred to the bone healing impairment, alone or with a biomaterial scaffold. Unrestricted or at least larger availability than autograft, higher cellular concentration, shorter surgical time and decreased associated morbidity are some of their major advantages.

Different cell-based solutions have been proposed, with different cell origins and technical specifications to prepare the final cellular product that will be implanted where bone regeneration is required. Solid preclinical data, adjusted to the cell product and the clinical indication, are needed to launch clinical trials, in the scope of obtaining the required authorization from regulators.

To submit to the regulatory authority and thus to enter into clinical trials, the researcher needs to prove that the cell product under investigation, or investigation medicinal product (IMP), complies with the quality standards that are requested by the medicines legislation. The documentation about standardization of the cell product that will be implanted needs to be prepared by the producer, which is in many cases the unit receiving the material from the orthopaedic surgeon after obtaining it in surgery (in case of bone marrow, the haematology units with capability to extract the cells and eventually expand or manipulate those). But the research team needs to support the file with preclinical data, both in vitro and in vivo, that prove the safety of the procedures to the cells, the safety to the host receiving those cells, the efficacy of these cells to produce bone (or cartilage, or desired tissue) in the laboratory, and the efficacy of these cells to produce bone in the host. Those aspects need to be supported by in vitro tests with the cells in culture, and in vivo tests usually in related animal models.

Safety of cell products needs to be clarified from manufacturing standards based on the Good Manufacturing Practices (GMP) European regulation [10]. Similar studies to conventional drugs are required to comply with the regulation, from in vitro testing to safety proved in animals. This includes general studies on pharmacological safety such as repeated dose toxicity (addressing general toxicity), reproductive toxicity (ensuring the potential harm in gonads), and carcinogenicity (confirming that no cell instability causes carcinogenetic uncontrolled development). However, living products such as those used in cell therapy raise concerns about potential safety issues after stimulated expansion, even in autologous cells. Therefore, safety issues require more knowledge about its mode of action. The persistence of cells in different sites where potential tumour formation could happen may require tracing the cells implanted in animals to clarify cell biodistribution and the potential for ectopic engraftment. However, the ultimate risk assessment (promoted by the European Medicine Agency (EMA) with Guidelines on Risk-based Approaches [11]) requires human phase I/IIa clinical studies to further confirm the risks related to a certain cell product are not increased. Finally, only clinical studies will be capable of confirming those issues.

Efficacy to obtain bone regeneration in preclinical models is also required to justify the use of a certain cell product in clinical trials. If the cells to be implanted are not capable of producing in vitro and in vivo bone regeneration, it would not be realistic to implant those in patients. Therefore, cell differentiation and mineralization are required as a preclinical proof of efficacy to further progress towards the clinical application.

\section{Safety, feasibility and efficacy end-points in clinical trials}

When preclinical studies are available and provide enough safety and efficacy data to support the start of clinical research in humans, clinical trials need to be designed to clinically confirm that the defined cell product is safe and efficacious in well-controlled groups of patients and indications. Therefore, the end-points of this research need to be clearly assigned in coherence with the available preclinical data.

The first step will be to confirm the safety of the product as well as to assess the feasibility of the proposed surgical procedure and technical practicalities. Therefore, one or several small-scale trials with safety and feasibility objectives will be first planned before a larger, confirmatory, efficacy and safety trial could be performed.

In order to decide on safety end points to be chosen, the investigators should address different sources of complications: the potential problems of the technique itself and problems attributed to the product, either at the local level or causing systemic complications. With regards to discard potential systemic problems, the time of assessment should be longer in order to be reasonably sure about the absence of dissemination and proliferation of the cell products outside their intended site of action.

The assessment of feasibility in a small-size trial is also crucial to ensure the success of the trial, as well as to standardize techniques and devices as much as needed, in case several surgeons and clinical sites are to be involved.

Efficacy end-points will depend on the disease to be treated and will include clinical outcome evaluation, both objective and subjective. In bone regenerative therapies, these include bone imaging, patient assessment of function, pain and daily activities, as well as frequently taking advantage of other 
available scores and questionnaires. It is acceptable to choose imaging parameters as the principal endpoint in regenerative therapy, but secondary efficacy end points related to functionality are also required to support the clinical outcomes of the study.

\section{Investigator driven clinical trials (IDCT) in advanced therapy medicinal products (ATMP)}

Advanced therapy medicinal products is a regulatory term used to designate a group of special biological therapies that are regulated under the medicines legislation and include gene therapy, cell therapy, and tissue engineered products either alone or combined with medical devices (Table 1).

As mentioned before, therapies based on cell and tissue engineered products are being developed mainly by academic investigators or groups in a non-commercial setting. A recent revision of clinical trials with ATMP [12] revised the 318 distinct clinical trials authorised in the EU in the period 2004-2010, involving 250 individual ATMPs, and found that the majority of them were sponsored by either academia $(50 \%)$ or charitable organizations $(10 \%)$. Of note, the remaining CT sponsored by commercial entities involve mainly small and medium enterprises or non-large pharmaceutical companies.

Unfortunately, the organization and execution of a clinical trial with medicines is a complex task that bears a heavy burden of legal, regulatory, financial and organizational requirements. Performing a clinical trial with ATMPs implies an extraordinary effort, especially when driven by academic, independent investigators willing to pursue the clinical research of a cell product.

Table 1 Medicinal products for human use considered advanced therapy medicinal products (ATMPs) in the European Regulation

Regulation (EC) No 1394/2007 of the European Parliament and of the Council of 13 November 2007 on advanced therapy medicinal products and amending Directive 2001/83/EC and Regulation (EC) No 726/2004

\footnotetext{
Advanced therapy medicinal products (ATMPs):

- a gene therapy medicinal product

— a somatic cell therapy medicinal product:

- contains or consists of cells or tissues that have been subject to substantial manipulation so that biological characteristics, physiological functions or structural properties relevant for the intended clinical use have been altered, or of cells or tissues that are not intended to be used for the same essential function(s) in the recipient and the donor

- is administered to human beings with a view to treating, preventing or diagnosing a disease through the pharmacological, immunological or metabolic action of its cells or tissues.

— a tissue engineered product, combined with a medical device:

- contains or consists of engineered cells or tissues, and

- is presented as having properties for, or is used in or administered to human beings with a view to regenerating, repairing or replacing a human tissue.
}

Regulation of clinical trials is well justified in order to give public guarantee of protection of patient's rights and ensure the credibility of the results. Nevertheless, many of the procedures established in clinical trial regulation were born to regulate the activities performed by pharmaceutical companies during the clinical development of new medicines with the intention to obtain a marketing authorisation, and they are dysfunctional in hospital or academic settings. This is a source of concern as it jeopardises the performance of independent clinical research, which is essential to answer relevant public health questions that are not in the agenda of pharmaceutical companies. The disproportionate administrative charges placed to an academic or hospital based research become even more apparent in the case where the investigated intervention is the potential clinical use of cell products prepared in hospital and not expected to be marketed.

When the investigator plans a clinical research with a cell product, one of the first questions should be the regulatory classification of the product. A therapeutic product consisting of cells or tissues could be regulated, depending on the characteristics of the product, either by the Tissues and Cells Directive (Directive 2004/23/EC) or by the Advanced Therapies Medicinal Products (ATMPs) Regulation (Regulation 1394/2007) [13]. The distinction between both types of products is relevant because it implies different administrative procedures to comply with. Nevertheless, it is not always easy to determine in which category a specific product falls. In some cases, it will be necessary to obtain a classification by the European Committee of Advanced Therapies (CAT) or to revise previous decisions on similar products released by this Committee.

The ATMP regulation establishes that a product will be an ATMP if it is a gene therapy, somatic cell therapy, or tissue engineered product, as defined in Table 1. In this definition, the concept of "substantial manipulation" of the cells becomes critical, as it determines if the product will be regulated as a medicine (an ATMP) or not. The Directive 2001/83/EC [14] contains the list of what is considered not to be a "substantial manipulation" and it includes procedures such as irradiation, concentration or cryopreservation. On the contrary, any cell expansion will always be considered as a "substantial manipulation" and therefore all products resulting from cell expansion will be considered as ATMP.

In addition, non-substantially manipulated cells or tissues, when they are not used for the same essential function or functions in the recipient as in the donor, will also be considered as ATMP. This is why the CAT has classified cases of non-manipulated cells as the autologous bone marrow-derived progenitor cells intended for treatment of patients with myocardial infarction as ATMP, or even concentrates of autologous bone marrow intended for the increase of new bone formation in a critical area of atrophic non-union.

The ATMP Regulation determines that medicinal products classified as ATMPs, when applying for a marketing 
authorisation, shall be regulated under the centralised European Marketing Authorisation procedure. The marketing authorisation will then be granted by the European Commission, following assessment by the EMA relevant scientific committees (CAT and CHMP). Nevertheless, this regulation empowers member states (MS) to authorise hospitals, on a national basis, the use of ATMPs in the absence of a marketing authorisation under the so-called hospital exemption clause (article 28 of the ATMP Regulation). The hospital exemption is applicable to all ATMPs that are prepared on a non-routine basis, prepared according to specific quality standards (equivalent to those for ATMPs with a centralised marketing authorisation), used within the same country, used in a hospital, used under the exclusive responsibility of a medical practitioner, and complying with an individual medical prescription for a custom-made product for an individual patient.

The hospital exemption is a very good provision to allow the use in hospitals of some non-commercial cell products that have enough scientific data to support its therapeutic use. However, a similar provision or exemption has not been implemented for clinical research; the regulatory requirements are the same for products under a commercial development pathway than for products being investigated in the academic or hospital environment without commercial intentions, with a final aim to just give scientific support to its use under the hospital exemption. This is even more striking if we realize that the academic research accounts for a very high proportion of the ATMP research and development.

Taking into account the complexity of clinical trials with ATMP, we think it is useful to share information and results about regulatory experiences of academic researchers, with the aim to facilitate the organization and performance of future clinical trials by other researchers.

\section{Before launching the trial: authorization by regulators and research ethics committees}

The performance of a clinical trial is subject to several international ethical codes and recommendations as well as to local legislations. The need to obtain the free and informed consent of any participant in the trial before any procedure and the need of previous approval of the whole project by a research ethics committee (REC) are both well-recognized obligations that are contained in international rules such as The Helsinki Declaration or the Council of Europe Additional Protocol. Those documents should be known and fully respected by all clinical researchers.

As far as the legislation is concerned, all member states of the EU have national legislation establishing that the performance of clinical trials with medicines are subject to a previous authorisation by a national competent authority (NCA). Relevant NCAs in Europe, participating in the EU FP7REBORNE project, are listed in Table 2. In 2001, a first European Clinical Trials Directive (Directive 2001/83/EC) [14] was published in order to establish common principles and harmonised procedures to all member states. The CT Directive will be soon repealed and a new piece of European legislation will enter into force. Both the European Parliament and the EU Council agreed at the end of 2013 on a new European Clinical Trial Regulation. Even with this new step forward towards a common and streamlined regulation of clinical trials in the EU, the competence for clinical trials approval will remain at the national level.

The current CT Directive, as well as the different national European legislations, define a clinical trial as "any systematic study of medicinal products in human subjects whether in patients or non-patient volunteers in order to discover or verify the effects of and/or identify any adverse reaction to investigational products, and/or study their absorption, distribution, metabolism and excretion in order to ascertain the efficacy and safety of the products". This is a very wide definition that includes any investigation with medicines, with the only exception of a pure observational study using an authorised medicine. Therefore, academic orthopaedic clinical trials targeting bone regeneration by the means of advanced therapy medicinal products are subject to authorisation by the national competent authority of the country (or countries) where the trial takes place.
Table 2 National competent authorities (NCA) or medicines agencies in the participant countries in the REBORNE project

\begin{tabular}{|c|c|c|}
\hline Country & NCA & Website \\
\hline Italy & Italian Medicines Agency & http://www.agenziafarmaco.gov.it/ \\
\hline France & $\begin{array}{l}\text { National Agency for the Safety of Medicine } \\
\text { and Health Products }\end{array}$ & http://www.ansm.sante.fr/ \\
\hline Spain & Spanish Agency for Medicines and Health Products & http://www.aemps.gob.es/ \\
\hline Germany & Paul Ehrlich Institute & http://www.pei.de/ \\
\hline Belgium & Federal Agency for Medicines and Health Products & http://www.fagg-afmps.be/ \\
\hline Norway & Norwegian Medicines Agency & http://www.legemiddelverket.no/ \\
\hline Netherlands & Medicines Evaluation Board & http://www.cbg-meb.nl/ \\
\hline Romania & National Medicines and Medical Devices Agency & http://www.anm.ro/ \\
\hline
\end{tabular}




\section{Procedure for clinical trial authorisation by NCAs}

Multinational clinical trial applications are assessed by NCAs and RECs from each participating country independently. No clinical trial may start in any country until both regulatory approval and ethics committee positive opinion are available. Usually, a third requirement is also necessary, which is a contract or economical agreement between the sponsor and investigators and trial sites.

Before submitting an application to any of these bodies, the investigator or the applicant should obtain a unique EudraCT number from the EudraCT Community Clinical Trial System [15], which identifies the protocol for a trial and whether it is conducted at a single site or at multiple sites in one or more European member states.

The core submission package to the NCAs is the same in all countries. It should include a cover letter, the EudraCT number, the application form, the protocol, the investigator's brochure, the investigational medicinal product dossier (IMPD) and the simplified IMPD. However, each country has its own submission and evaluation particularities, which may require specific documents, additional steps in the regulatory procedure as well as additional competent authorities involved in the process. This type of assessment generates a lot of work to organise a multinational trial in the EU, and even runs into a risk of divergent decisions (approval, conditional approval, or refusal) for the same clinical trial in different MS.

Differences are even greater for the RECs submissions, as the procedure for ethics committee approval is different in each MS and even between different RECs in the same country. Generally, there can be a central ethics committee, regional ethics committees and/or local/institutional ethics committees. There are currently about 1,000 RECs in Europe [16].

RECs should consider several aspects when preparing an opinion, such as the relevance of the clinical trial and the trial design, whether the evaluation of the anticipated benefits and risk is satisfactory, the protocol, the suitability of the investigator and supporting staff, the investigator's brochure, the quality of the facilities where the clinical trial would take place, the adequacy and completeness of the written information to be given and the procedure to be followed for the purpose of obtaining informed consent, provision for indemnity or compensation in the event of injury or death attributable to a clinical trial, as well as any insurance or indemnity to cover the liability of the investigator and sponsor, and the arrangements for the recruitment of subjects.

In spite of this common approach for NCAs and RECs, the investigator will be obliged to find the specific instructions on what and how to submit to all concerned NCAs and RECs, as well as pay the different fees that are requested. Fortunately, it is rather common that both, the RECs and the NCAs, accept requests for fee waivers or fee discounts in case of non- commercial trials, rare diseases, ATMP or other explicit conditions that could be present in these orthopaedic trials.

In summary, a substantial and experienced support is needed to deal with multisite or multinational trial approvals and this should be carefully considered in the trial budget and planning.

\section{The European regulatory pathway in bone regeneration}

The EU Heads of Medicines Agencies (HMA) established a system called the voluntary harmonised procedure (VHP). This system allows a joint assessment of a clinical trial by the concerned authorities, harmonising the procedures and the decision-making process to ensure the protection of participants as well as the scientific value of trials in the EU [17]. Even through voluntary harmonised procedures, each national competent authority remains responsible for the approval of the clinical trial application in its own country; therefore the VHP takes place before the initial phase of the national process.

The procedure started in 2009 and has been successful, as shown by the increase of multinational trials using this method as well as the future formalisation of this approach in the new European regulation. According to VHP statistics, only $10 \%$ of the trials following this approach are non-commercial trials, which could suggest this is an unknown or non-attractive pathway to the academic investigators. Our group has used a VHP procedure for a multicentric, multinational cell therapy trial conducted in four member states (ORTHO 2 trial, EudraCT2012-002010-39) and found several advantages in comparison with pure national approvals.

The first positive result from the VHP is a direct consequence of a single common assessment being done by all European NCAs in a joint exercise, namely, the obligation of the NCAs to agree on the distinction of what is "needed to know" from what is just "interesting to know" before a trial is approved. We think that NCAs probably coincide on what needs to be requested before allowing a product to be marketed, but in our experience there is some room for differences between NCAs about the level of requirements before approving a clinical trial (ie. documentation about the quality of the ATMP product or preclinical package to support safety or preclinical data in animal models supporting efficacy in a specific human condition).

The second positive result from our experience is the demonstration that a group of clinical researchers could join together in a single multicenter multinational trial intended to provide common evidence about a potential clinical use in bone regeneration, using an ATMP product from academic production centres associated with the different clinical sites, in a model of research that resembles future therapeutic use under the hospital exemption. 


\section{Conclusions}

A substantial interest and development of bone cell therapy can be found in many orthopaedic surgeons and departments. Most specialists are convinced that bone regeneration may be a good opportunity to help our patients and evolve towards a more biological approach of orthopaedic surgery and traumatology. In reviewing the current epidemiology of musculoskeletal problems, different hypothesis can be identified. Better definition of patients and diagnoses that may become therapeutic targets of these advanced therapies is required. But before bone regeneration therapies can be adequately applied to the general population, safety and efficacy issues must be solved in the laboratory, and clinical trials must be conducted to confirm the foreseen benefit in specific patient groups. This risk/benefit assessment is not yet available for most proposals, and significant opportunities to perform clinical trials on cell therapy can be found by Orthopaedic surgeons with interest in bone regeneration.

Acknowledgments This work was supported in part by the European Commission, Seventh Framework Programme (FP7), through the REBORNE Project, grant agreement no. 241879.

Conflict of interest disclosure The authors do not have anything to disclose.

Open Access This article is distributed under the terms of the Creative Commons Attribution License which permits any use, distribution, and reproduction in any medium, provided the original author(s) and the source are credited.

\section{References}

1. Gomez-Barrena E, Rosset P, Muller I, Giordano R, Bunu C, Layrolle P, Konttinen YT, Luyten FP (2011) Bone regeneration: stem cell therapies and clinical studies in orthopaedics and traumatology. J Cell Mol Med 15(6):1266-1286. doi:10.1111/j.1582-4934.2011.01265.x

2. Salomon JA, Vos T, Hogan DR, Gagnon M, Naghavi M, Mokdad A, Begum N, Shah R, Karyana M, Kosen S, Farje MR, Moncada G, Dutta A, Sazawal S, Dyer A, Seiler J, Aboyans V, Baker L, Baxter A, Benjamin EJ, Bhalla K, Bin Abdulhak A, Blyth F, Bourne R, Braithwaite T, Brooks P, Brugha TS, Bryan-Hancock C, Buchbinder R, Burney P, Calabria B, Chen H, Chugh SS, Cooley R, Criqui MH, Cross M, Dabhadkar KC, Dahodwala N, Davis A, Degenhardt L, DiazTorne C, Dorsey ER, Driscoll T, Edmond K, Elbaz A, Ezzati M, Feigin V, Ferri CP, Flaxman AD, Flood L, Fransen M, Fuse K, Gabbe BJ, Gillum RF, Haagsma J, Harrison JE, Havmoeller R, Hay RJ, Hel-Baqui A, Hoek HW, Hoffman H, Hogeland E, Hoy D, Jarvis D, Karthikeyan G, Knowlton LM, Lathlean T, Leasher JL, Lim SS, Lipshultz SE, Lopez AD, Lozano R, Lyons R, Malekzadeh R, Marcenes W, March L, Margolis DJ, McGill N, McGrath J, Mensah GA, Meyer AC, Michaud C, Moran A, Mori R, Murdoch ME, Naldi L, Newton CR, Norman R, Omer SB, Osborne R, Pearce N, Perez-Ruiz F, Perico N, Pesudovs K, Phillips D, Pourmalek F, Prince M, Rehm JT, Remuzzi G, Richardson K, Room R, Saha S, Sampson U, Sanchez-Riera L, Segui-Gomez M,
Shahraz S, Shibuya K, Singh D, Sliwa K, Smith E, Soerjomataram I, Steiner T, Stolk WA, Stovner LJ, Sudfeld C, Taylor HR, Tleyjeh IM, van der Werf MJ, Watson WL, Weatherall DJ, Weintraub R, Weisskopf MG, Whiteford H, Wilkinson JD, Woolf AD, Zheng ZJ, Murray CJ, Jonas JB (2012) Common values in assessing health outcomes from disease and injury: disability weights measurement study for the Global Burden of Disease Study 2010. Lancet 380(9859):2129-2143. doi:10.1016/s01406736(12)61680-8

3. WHO (2003) The burden of musculoskeletal conditions at the start of the new millennium. WHO technical report series 919. World Health Organization, Geneva

4. Mock C, Cherian MN (2008) The global burden of musculoskeletal injuries: challenges and solutions. Clin Orthop Relat Res 466(10): 2306-2316. doi:10.1007/s11999-008-0416-Z

5. Heinegard D, Johnell O, Lidgren L, Nilsson O, Rydevik B, Wollheim F, Akesson K (1998) The bone and joint decade 2000-2010. Acta Orthop Scand 69(3):219-220

6. The Bone and Joint Decade (2014) http://bjdonline.org. Accessed 24 Feb 2014

7. Mills LA, Simpson AH (2013) The relative incidence of fracture nonunion in the Scottish population (5.17 million): a 5-year epidemiological study. BMJ Open 3(2):e002276. doi:10.1136/bmjopen-2012-002276

8. Kanis JA, Johnell O, Oden A, Sembo I, Redlund-Johnell I, Dawson A, De Laet C, Jonsson B (2000) Long-term risk of osteoporotic fracture in Malmö. Osteoporos Int 11(8):669-674

9. Alves SM, Economou T, Oliveira C, Ribeiro AI, Neves N, GomezBarrena E, Pina MF (2013) Osteoporotic hip fractures: bisphosphonates sales and observed turning point in trend. A population-based retrospective study. Bone 53(2):430-436. doi:10. 1016/j.bone.2012.12.014

10. Crisan M, Chen CW, Corselli M, Andriolo G, Lazzari L, Peault B (2009) Perivascular multipotent progenitor cells in human organs. Ann NY Acad Sci 1176:118-123. doi:10.1111/j.1749-6632.2009.04967.x

11. EMA European Medicines Agency. Risk-management plans. http:// www.ema.europa.eu/ema/index.jsp?curl=pages/regulation/document_ listing/document_listing_000360.jsp. Accessed 12 Mar 2014

12. Maciulaitis R, D'Apote L, Buchanan A, Pioppo L, Schneider CK (2012) Clinical development of advanced therapy medicinal products in Europe: evidence that regulators must be proactive. Mol Ther: $\mathrm{J}$ Am Soc Gene Ther 20(3):479-482. doi:10.1038/mt.2012.13

13. Dominici M, Le Blanc K, Mueller I, Slaper-Cortenbach I, Marini F, Krause D, Deans R, Keating A, Prockop D, Horwitz E (2006) Minimal criteria for defining multipotent mesenchymal stromal cells. The International Society for Cellular Therapy position statement. Cytotherapy 8(4):315-317. doi:10.1080/14653240600855905

14. Giannoni P, Muraglia A, Giordano C, Narcisi R, Cancedda R, Quarto R, Chiesa R (2009) Osteogenic differentiation of human mesenchymal stromal cells on surface-modified titanium alloys for orthopedic and dental implants. Int J Artif Organs 32(11):811-820

15. Xin Y, Wang YM, Zhang H, Li J, Wang W, Wei YJ, Hu SS (2010) Aging adversely impacts biological properties of human bone marrow-derived mesenchymal stem cells: implications for tissue engineering heart valve construction. Artif Organs 34(3):215-222. doi:10.1111/j.1525-1594. 2009.00824.x

16. Druml C, Wolzt M, Pleiner J, Singer EA (2009) Research ethics committees in Europe: trials and tribulations. Intensive Care Med 35(9):1636-1640. doi:10.1007/s00134-009-1544-y

17. HMAs Clinical Trials Facilitation Group (2013) Guidance document for sponsors for a voluntary harmonisation procedure (VHP) for the assessment of multinational clinical trial applications. http://www. hma.eu/fileadmin/dateien/Human_Medicines/01-About_HMA/ Working_Groups/CTFG/2013_04_C_TFG_VHP_v3.pdf. Accessed 12 Mar 2014 